\title{
Cerebral metabolism is not affected by moderate hyperventilation in patients with traumatic brain injury
}

\author{
Giovanna Brandi ${ }^{*}$ (D), Nino Stocchetti ${ }^{2}$, Alberto Pagnamenta ${ }^{3}$, Federica Stretti ${ }^{1,4}$, Peter Steiger ${ }^{1}$ \\ and Stephanie Klinzing ${ }^{1}$
}

\begin{abstract}
Background: Hyperventilation-induced hypocapnia (HV) reduces elevated intracranial pressure (ICP), a dangerous and potentially fatal complication of traumatic brain injury (TBI). HV decreases the arteriolar diameter of intracranial vessels, raising the risk of cerebral ischemia. The aim of this study was to characterize the effects of moderate shortterm HV in patients with severe TBI by using concomitant monitoring of cerebral metabolism, brain tissue oxygen tension $\left(\mathrm{PbrO}_{2}\right)$, and cerebral hemodynamics with transcranial color-coded duplex sonography (TCCD).

Methods: This prospective trial was conducted between May 2014 and May 2017 in the surgical intensive care unit (ICU) at the University Hospital of Zurich. Patients with nonpenetrating TBI older than 18 years of age with a Glasgow Coma Scale (GCS) score $<9$ at presentation and with ICP monitoring, $\mathrm{PbrO}_{2}$, and/or microdialysis (MD) probes during ICU admission within $36 \mathrm{~h}$ after injury were included in our study. Data collection and TCCD measurements were performed at baseline (A), at the beginning of moderate $\mathrm{HV}(\mathrm{C})$, after 50 min of moderate HV (D), and after return to baseline (E). Moderate HV was defined as arterial partial pressure of carbon dioxide 4-4.7 kPa. Repeated measures analysis of variance was used to compare variables at the different time points, followed by post hoc analysis with Bonferroni adjustment as appropriate.
\end{abstract}

Results: Eleven patients (64\% males, mean age $36 \pm 14$ years) with an initial median GCS score of 7 (IQR 3-8) were enrolled. During HV, ICP and mean flow velocity (CBFV) in the middle cerebral artery decreased significantly. Glucose, lactate, and pyruvate in the brain extracellular fluid did not change significantly, whereas $\mathrm{PbrO}_{2}$ showed a statistically significant reduction but remained within the normal range.

Conclusion: Moderate short-term hyperventilation has a potent effect on the cerebral blood flow, as shown by TCCD, with a concomitant ICP reduction. Under the specific conditions of this study, this degree of hyperventilation did not induce pathological alterations of brain metabolites and oxygenation.

Trial registration: NCT03822026. Registered on 30 January 2019.

Keywords: Traumatic brain injury, Hyperventilation, Intracranial pressure, Brain metabolites, Brain oxygenation, Transcranial color-coded duplex sonography

\footnotetext{
* Correspondence: giovanna.brandi@usz.ch

${ }^{1}$ Institute for Intensive Care Medicine, University Hospital of Zurich,

Rämistrasse 100, 8091 Zurich, Switzerland

Full list of author information is available at the end of the article
}

(C) The Author(s). 2019 Open Access This article is distributed under the terms of the Creative Commons Attribution 4.0 International License (http://creativecommons.org/licenses/by/4.0/), which permits unrestricted use, distribution, and reproduction in any medium, provided you give appropriate credit to the original author(s) and the source, provide a link to the Creative Commons license, and indicate if changes were made. The Creative Commons Public Domain Dedication waiver (http://creativecommons.org/publicdomain/zero/1.0/) applies to the data made available in this article, unless otherwise stated. 


\section{Introduction}

Hyperventilation-induced arterial hypocapnia (HV) has been used for decades in neuroanesthesia and neurointensive care, especially in the management of patients with severe traumatic brain injury (TBI) and concomitant elevated intracranial pressure (ICP). Increased alveolar ventilation induces a dose-response decrease in arterial partial pressure of carbon dioxide $\left(\mathrm{PaCO}_{2}\right)$, causing a parallel reduction of carbon dioxide partial pressure in the extracellular brain compartment with tissue alkalosis. This results in vasoconstriction of the cerebral arterioles [1, 2]. Consequently, cerebral blood flow (CBF), cerebral blood volume (CBV), and ultimately ICP decrease.

The most relevant criticism of the use of $\mathrm{HV}$ is the risk of cerebral ischemia and hypoxia, especially in the acute phase of TBI [3]. This risk has been documented in several studies $[4,5]$, but the net effects of $\mathrm{HV}$ on regional CBF and metabolism are still debated [6].

Despite those concerns, $\mathrm{HV}$ is still widely used, even in the absence of elevated ICP and without brain oxygenation monitoring [7]. However, there is an international consensus that $\mathrm{HV}$ could have deleterious effects, especially by reducing CBF and brain oxygenation. To minimize this risk, HV should be used only to counteract the raised ICP, rather than prophylactically, and only with appropriate monitoring of CBF and/or oxygenation [8-11]. While continuous global measurements of $\mathrm{CBF}$ are not feasible at the bedside, cerebral blood flow velocity in the middle cerebral artery (CBFV) may be measured by transcranial Doppler and has been used to monitor the effects of hypocapnia [12, 13]. The present study was conducted to quantify potential adverse effects of moderate short-term $\mathrm{HV}$ during the acute phase of severe TBI on cerebral hemodynamics, oxygenation, and metabolism.

\section{Methods}

The Institutional Ethics Committee of Zurich approved the research protocol of this prospective clinical trial (KEK-ZH 2012-0542). Informed consent was obtained from the patients' next of kin prior to study enrollment and/or from the patients after ICU discharge.

\section{Patient population and initial stabilization}

Inclusion criteria involved patients ( $\geq 18$ years of age) with nonpenetrating head injury, with initial GCS score $<9$ prior to sedation and intubation, extended neuromonitoring with ICP, $\mathrm{PbrO}_{2}$, and/or microdialysis probes, undergoing invasive mechanical ventilation with fraction of inspired oxygen $<60 \%$ and positive end-expiratory pressure $<15$ $\mathrm{cmH}_{2} \mathrm{O}$. Exclusion criteria were decompressive craniectomy, pregnancy, preexisting neurologic disease, previous TBI, acute cardiovascular disease, severe respiratory failure, acute or chronic liver disease, sepsis, and failure to obtain satisfactory bilateral TCCD signals. Patients with persisting hypovolemia or hemodynamic instability despite previous fluid resuscitation (defined as global end-diastolic volume index $<680 \mathrm{ml} / \mathrm{m}^{2}$, central venous oxygen saturation $\left[\mathrm{ScvO}_{2}\right]<60 \%$, or increase in mean arterial blood pressure $[\mathrm{MAP}]>15 \%$ after passive leg raise test) were excluded. All patients were treated according to a cerebral perfusion orientated protocol aiming to achieve cerebral perfusion pressure $(\mathrm{CPP})>70 \mathrm{mmHg}, \mathrm{ICP} \leq 20 \mathrm{mmHg}$, and $\mathrm{PbrO}_{2}>15$ mmHg. $\mathrm{PaCO}_{2}$ was targeted at $4.8-5.2 \mathrm{kPa}$.

\section{Monitoring}

MAP, ICP, CPP, arterial oxygen saturation $\left(\mathrm{SaO}_{2}\right)$, end-tidal $\mathrm{CO}_{2}\left(\right.$ etCO $\left.\mathrm{C}_{2}\right)$, and $\mathrm{PbrO}_{2}$ were continuously monitored. ICP was measured with a fiberoptic device (Camino, San Diego, CA, USA) and $\mathrm{PbrO}_{2}$ with a Clark-type microcatheter (Licox GmbH, Kiel, Germany).

Cerebral microdialysis (MD) was performed using a catheter (CMA70; Microdialysis, Solna, Sweden) with a membrane length of $10 \mathrm{~mm}$ and a molecular mass cutoff of $20 \mathrm{kDa}$, which was perfused by a microinjection pump (CMA 106; Microdialysis) with artificial cerebrospinal fluid at a flow rate of $0.3 \mu \mathrm{l} / \mathrm{min}$. Samples were collected every hour and immediately analyzed for glucose, lactate, and pyruvate with a bedside MD analyzer (CMA 600; CMA/Microdialysis). Sampling was performed at 1 -h intervals in order to allow the detection of sufficient concentration of analytes in the microdialysate. ICP, $\mathrm{PbrO}_{2}$, and MD catheters were placed in the white frontal matter, usually on the side of the brain with more significant injury. The correct position of the catheters was confirmed by computed tomography.

TCCD examinations of the middle cerebral artery (MCA) were performed bilaterally through the transtemporal acoustic window by two experienced physicians (SK, GB) according to standard techniques [14, 15] using a 2-MHz Probe (Philips CX 50; Philips Healthcare, Andover, MA, USA). Three repeated measurements of the peak systolic velocity (PSV) and end-diastolic velocity (EDV) were performed for each side. The device automatically calculated CBFV and pulsatility index (PI). PI was chosen for its high predictive value in case of increased ICP and low CPP [16].

\section{Study protocol}

Patients were enrolled in the study within $36 \mathrm{~h}$ of sustaining trauma. Under baseline conditions, a TCCD examination was performed, and all parameters were recorded (Fig. 1, point A). The alveolar ventilation was then increased over a 10-min period to obtain moderate $\mathrm{HV}$ by a stepwise increase in tidal volume and respiratory rate until a reduction of etCO $\mathrm{C}_{2}$ of $0.7 \mathrm{kPa}$ (Fig. 1, point B) was achieved. 


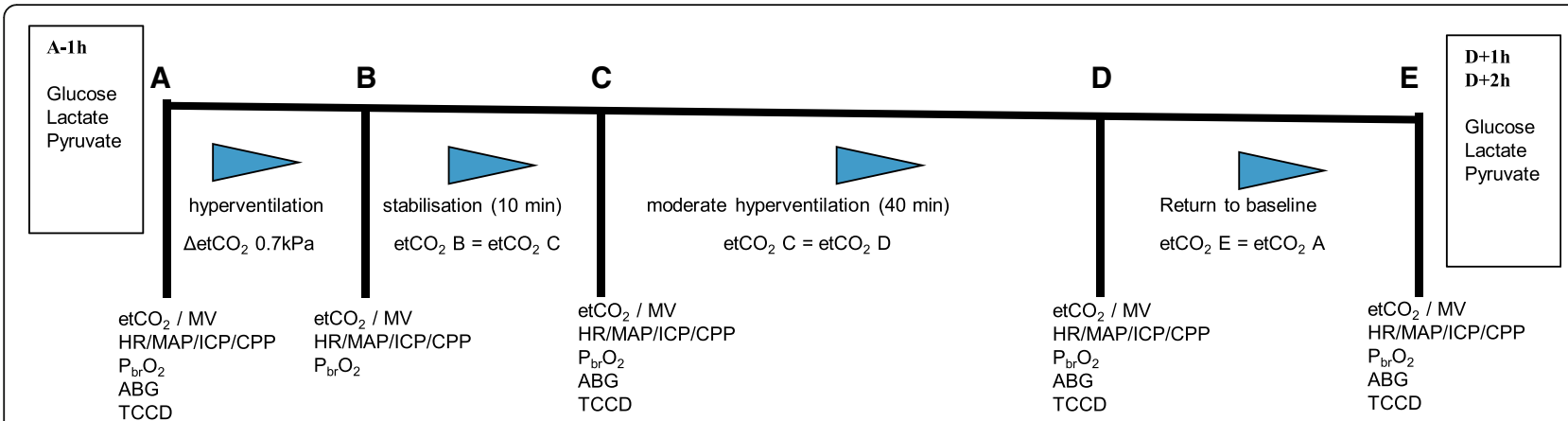

Fig. 1 Study protocol. At different time points, several variables were collected and transcranial color-coded duplex sonography (TCCD) measurements were performed. $\mathbf{A}=$ Baseline. $\mathbf{B}=$ Increasing minute ventilation. $\mathbf{C}=$ Begin moderate hyperventilation with target $\mathrm{PaCO}_{2} 4-4.7$ $\mathrm{kPa}$. $\mathbf{D}=$ After moderate hyperventilation for $50 \mathrm{~min} . \mathbf{E}=$ Return to baseline. Glucose, lactate, and pyruvate concentrations in the extracellular fluid were sampled by microdialysis $1 \mathrm{~h}$ before $\mathrm{A}(\mathrm{A}-1 \mathrm{~h})$ and $1 \mathrm{~h}(\mathrm{D}+1 \mathrm{~h})$ and $2 \mathrm{~h}$ after $\mathrm{D}(\mathrm{D}+2)$. et $\mathrm{CO}_{2}$ End-tidal $\mathrm{CO}_{2}(\mathrm{kPa}), M V \mathrm{Minute}$ ventilation (L/min), HR Heart rate (beats/min), MAP Mean arterial pressure $(\mathrm{mmHg}), I C P$ Intracranial pressure $(\mathrm{mmHg}), C P P$ Cerebral perfusion pressure $(\mathrm{mmHg}), \mathrm{PbrO}_{2}$ Brain tissue oxygen tension $(\mathrm{mmHg}), A B G$ A Arterial blood gas analysis

After 10 min of stable etCO $\mathrm{C}_{2}$, a second TCCD measurement was made (beginning of $\mathrm{HV}$; Fig. 1, point $\mathrm{C}$ ). The etCO $\mathrm{O}_{2}$ value was kept stable for $40 \mathrm{~min}$, followed by a third TCCD examination (Fig. 1, point D). Finally, normoventilation was reestablished over $10 \mathrm{~min}$, and all variables were allowed to return to baseline (Fig. 1, point E). A final TCCD examination was conducted at this time point. At each time point, MAP, ICP, CPP, $\mathrm{PbrO}_{2}$, $\mathrm{SpO}_{2}$, and etCO $\mathrm{O}_{2}$ were recorded.

Microdialysate samples for glucose, lactate, and pyruvate concentrations were collected $1 \mathrm{~h}$ before A (A - 1 h) as a baseline measurement and $1 \mathrm{~h}(\mathrm{D}+1 \mathrm{~h})$ and $2 \mathrm{~h}$ $(\mathrm{D}+2 \mathrm{~h})$ after $\mathrm{D}$ to detect possible changes induced by moderate HV. Arterial blood gas tests (ABG) were obtained at points $\mathrm{A}, \mathrm{C}, \mathrm{D}$, and $\mathrm{E}$ to monitor the changes of $\mathrm{pH}$ and $\mathrm{PaCO}_{2}$.

\section{Statistical analysis}

Data were analyzed to produce mean \pm SD or median with IQR, unless otherwise indicated. Repeated-measures analysis of variance (ANOVA) was used to compare all variables. When the $F$-ratio of the ANOVA reached a critical level (corresponding to $p<0.05$ ), post hoc analysis with Bonferroni adjustment was used. All tests were performed two-sided, and $p<0.05$ was considered statistically significant. Statistical analysis was performed using Stata version 12.1 software (StataCorp LP, College Station, TX, USA).

\section{Results}

\section{Demographic data}

During the study period, 628 patients with TBI were admitted to the surgical ICU. A breakdown of reasons for exclusion is presented in Fig. 2. Eleven patients with severe TBI were included; $64 \%$ were males, with a mean age of $36 \pm 14$ years. The median first GCS score was 7 (IQR 3-8). The admission computed tomographic (CT) scan identified several brain lesions, very often combined. An epidural hematoma was diagnosed in three patients (27\%), a subdural hematoma in seven (64\%), contusions in eight (73\%), and edema/swelling in three (27\%).

On average, the Injury Severity Score (ISS) was $31 \pm$ 11, and the Simplified Acute Physiology Score (SAPS) II $24 \mathrm{~h}$ after TBI was, on average, $48 \pm 9$. The study was performed, on average, $23 \mathrm{~h}$ after TBI.

\section{Ventilation parameters}

Changes in $\mathrm{PaCO}_{2}$ during the test and other respiratory variables are shown in Table 1.

\section{Effects of hyperventilation on systemic and cerebral hemodynamics}

MAP and HR (Table 2) did not change significantly during the study. Mean ICP was $16 \pm 6 \mathrm{mmHg}$ (A), decreased significantly to $8 \pm 6 \mathrm{mmHg} \quad(p<0.0001)$ during $\mathrm{C}$, and remained stable during $\mathrm{D}(10 \pm 7 \mathrm{mmHg}$; $p=0.30)$. On return to normoventilation (E), ICP increased significantly to $14 \pm 6 \mathrm{mmHg}(p=0.003 \mathrm{com}$ pared with $\mathrm{D})$ and was similar to $\mathrm{A}(p=0.06)$.

\section{Effects of hyperventilation on mean flow velocity and PI in the middle cerebral artery}

TCCD measurements in the right and left MCAs were analyzed separately. CBFV was $81 \pm 23 \mathrm{~cm} / \mathrm{s}$ and $80 \pm 22$ in the right and left MCAs, respectively. During C, CBFV decreased to $69 \pm 21 \mathrm{~cm} / \mathrm{s}$ in the right MCA $(p=0.0002)$ and to $66 \pm 17 \mathrm{~cm} / \mathrm{s}$ in the left MCA $(p=0.006)$. CBFV did not change significantly during $\mathrm{D}(71 \pm 20 \mathrm{~cm} / \mathrm{s}, p=0.38$, and $63 \pm 15 \mathrm{~cm} / \mathrm{s}, p=0.48$, in the right and left MCA, respectively) compared with C. During E, CBFV was $77 \pm 28 \mathrm{~cm} /$ $\mathrm{s}(p=0.21$, compared with $\mathrm{D})$ and $75 \pm 24 \mathrm{~cm} / \mathrm{s}(p=0.005$, compared with $\mathrm{D})$ at the right and left sides, respectively. 


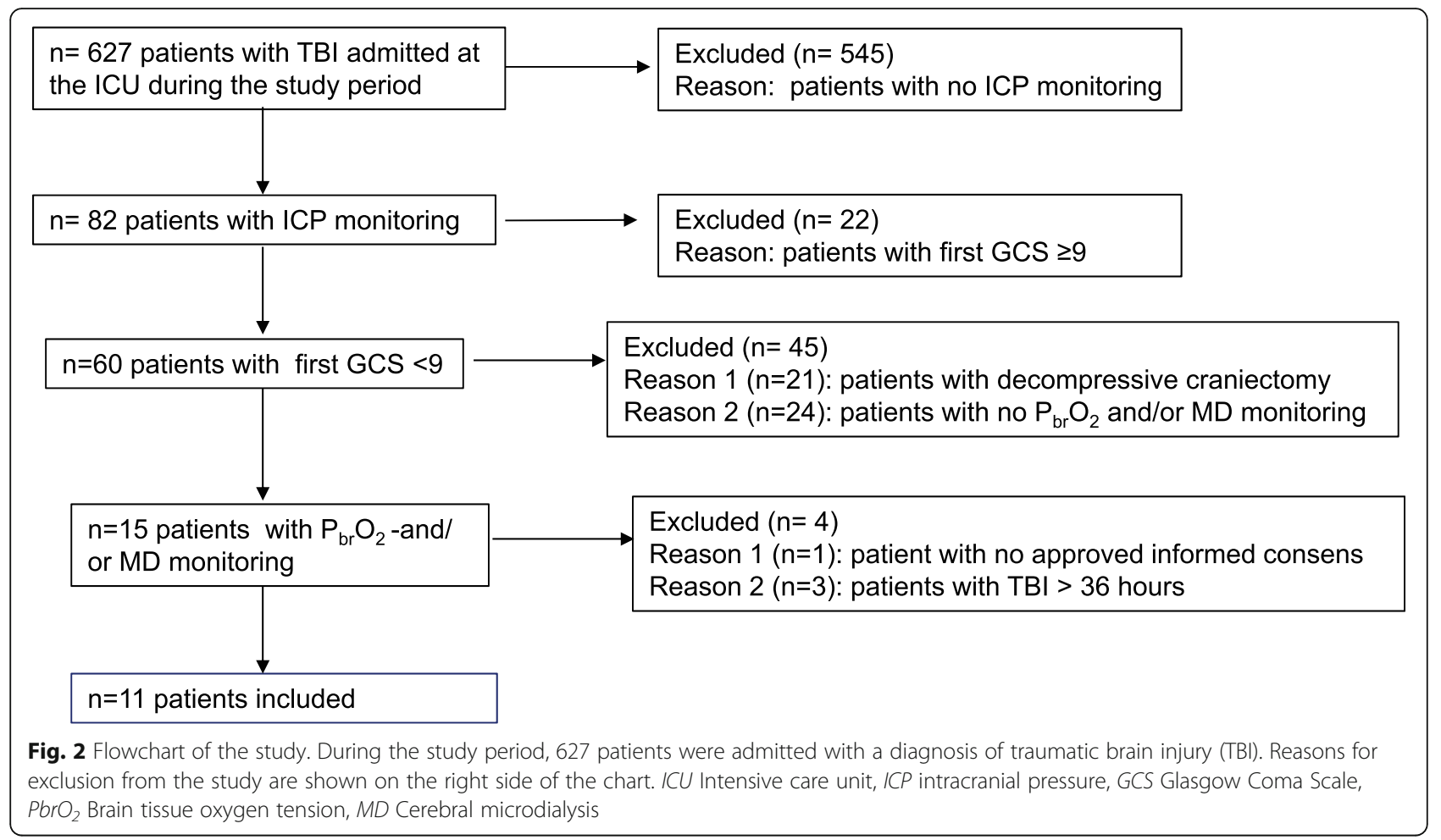

PI was $1.03 \pm 0.17$ and $0.96 \pm 0.15$ in the right and left MCAs, respectively. During the study, PI did not change significantly in the right MCA (Table 3 ). In the left MCA, PI remained stable during C $(1.06 \pm 0.10, p=$ 0.056 , compared with $\mathrm{A}$ ), increased significantly during $\mathrm{D}(1.07 \pm 0.14, p<0.03$, compared with $\mathrm{A})$, and remained stable during $\mathrm{E}(1.02 \pm 0.14, p=0.12$, compared with $\mathrm{D})$.

Changes of PSV and EDV on both sides are shown in Table 3.

\section{Brain tissue oxygen tension and cerebral metabolism}

$\mathrm{PbrO}_{2}$ and $\mathrm{MD}$ were measured in 10 and 9 patients, respectively. Eight patients got $\mathrm{PbrO}_{2}$ and $\mathrm{MD}$ simultaneously, and both probes were placed close to each other. The parenchyma surrounding the probes appeared normal on the CT scan in nine patients, seven of them with both $\mathrm{PbrO}_{2}$ and $\mathrm{MD}$ monitoring, one with only MD monitoring, and one with only $\mathrm{PbrO}_{2}$. In two cases, the parenchyma surrounding the probes appeared pathological; one of them had $\mathrm{PbrO}_{2}$ and MD probes inserted, and one only a $\mathrm{PbrO}_{2}$ probe.

Mean $\mathrm{PbrO}_{2}$ was $32 \pm 10 \mathrm{mmHg}$; it remained stable during $\mathrm{C}(33 \pm 10 p=0.50)$, decreased during D $(30 \pm 8 \quad p=0.003$, compared with C), and remained stable during $\mathrm{E}(30 \pm 8 p=0.90$ compared with D) (Table 2).

Table 1 Respiratory variables

\begin{tabular}{|c|c|c|c|c|c|}
\hline$n=11$ & $\begin{array}{l}\text { A } \\
\text { Baseline }\end{array}$ & $\begin{array}{l}\text { B } \\
\text { Minute ventilation }\end{array}$ & $\begin{array}{l}\text { C } \\
\text { Moderate hyperventilation }\end{array}$ & $\begin{array}{l}\text { D } \\
50 \text { min of moderate hyperventilation }\end{array}$ & $\begin{array}{l}\text { E } \\
\text { Return to baseline }\end{array}$ \\
\hline$\overline{\text { etCO}_{2}(\mathrm{kPa})}$ & $5.0(0.7)$ & $4.3(0.6)^{*}$ & $4.2(0.6)^{* \S}$ & $4.0(0.7)^{* \S}$ & $4.7(0.7)^{* 5 \uparrow \mp}$ \\
\hline $\mathrm{MV}(\mathrm{L} / \mathrm{min})$ & $6.9(1.4)$ & $8.6(1.6)^{*}$ & $8.7(1.7)^{*}$ & $8.4(1.5)^{*}$ & $6.8(1.4)^{\xi 91 T}$ \\
\hline $\mathrm{pH}$ & $7.37(0.09)$ & & $7.45(0.02)^{*}$ & $7.46(0.03)^{* \curvearrowleft}$ & $7.41(0.03)^{q^{\mp 7}}$ \\
\hline $\mathrm{PaCO}_{2}(\mathrm{kPa})$ & $5.0(0.2)$ & & $4.3(0.2)^{*}$ & $4.1(0.4)^{* \pi}$ & $4.7(0.4)^{* 9.97}$ \\
\hline $\mathrm{PaO}_{2}(\mathrm{kPa})$ & $17.2(1.5)$ & & $17.9(1.9)$ & $18.8(2.3)^{* \pi}$ & $17.4(1.2)^{\mp}$ \\
\hline
\end{tabular}

Abbreviations: $A$ Baseline, $B$ Increasing minute ventilation, $C$ Begin moderate hyperventilation with target $\mathrm{PaCO}_{2} 4-4.7 \mathrm{kPa}, D$ After moderate hyperventilation for $50 \mathrm{~min}, E$ Return to baseline, et $\mathrm{CO}_{2}$ End-tidal $\mathrm{CO}_{2}, \mathrm{MV}$ Minute ventilation (L/min), $\mathrm{PaCO}_{2}$ Partial pressure arterial carbon dioxide $(\mathrm{kPa}), \mathrm{PaO}_{2} \mathrm{Partial}$ pressure arterial oxygen $(\mathrm{kPa})$

Data are expressed as mean (SD)

* $p<0.05$ compared with $A$

${ }_{5} p<0.05$ compared with $B$

" $p<0.05$ compared with $C$

${ }^{\mathrm{F}} p<0.05$ compared with $\mathrm{D}$ 
Table 2 Systemic and cerebral hemodynamics

\begin{tabular}{|c|c|c|c|c|c|}
\hline$n=11$ & $\begin{array}{l}\text { A } \\
\text { Baseline }\end{array}$ & $\begin{array}{l}\text { B } \\
\text { Minute } \\
\text { ventilation }\end{array}$ & $\begin{array}{l}\text { C } \\
\text { Moderate hyperventilation }\end{array}$ & $\begin{array}{l}\text { D } \\
50 \text { min of moderate hyperventilation }\end{array}$ & $\begin{array}{l}\text { E } \\
\text { Return to baseline }\end{array}$ \\
\hline HR (beats/min) & $72(16)$ & $72(17)$ & $71(17)$ & $71(17)$ & $66(16)$ \\
\hline MAP $(\mathrm{mmHg})$ & $92(10)$ & $92(10)$ & $93(12)$ & $90(10)$ & $94(13)$ \\
\hline ICP (mmHg) & $16(6)$ & $8(5)^{*}$ & $8(6)^{*}$ & $10(7)^{*}$ & $14(6)^{591 \mp}$ \\
\hline $\mathrm{CPP}(\mathrm{mmHg})$ & $77(9)$ & $84(9)^{*}$ & $85(10)^{*}$ & $81(14)$ & $80(11)^{5 \bullet}$ \\
\hline $\mathrm{PbrO}_{2}(\mathrm{mmHg})$ & $32(10)$ & $33(9)$ & $33(10)$ & $30(8)^{5 \uparrow}$ & $30(8)^{\S}$ \\
\hline
\end{tabular}

Abbreviations: $A$ Baseline, $B$ Increasing minute ventilation, $C$ Begin moderate hyperventilation with target $\mathrm{PaCO}{ }_{2} 4-4.7 \mathrm{kPa}, D$ After moderate hyperventilation for $50 \mathrm{~min}, E$ Return to baseline, HR Heart rate (beats/min), MAP Mean arterial pressure $(\mathrm{mmHg}), I C P$ Intracranial pressure (mmHg), CPP Cerebral perfusion pressure $(\mathrm{mmHg}), \mathrm{PbrO}_{2}$ Brain tissue oxygen tension $(\mathrm{mmHg})$

$N=11$ patients; $+=10$ patients. Data are expressed as mean (SD)

* $p<0.05$ compared with $\mathrm{A}$

$\S p<0.05$ compared with $\mathrm{B}$

I $p<0.05$ compared with $C$

$\mp p<0.05$ compared with D

The mean extracellular fluid concentrations of glucose, lactate, pyruvate, and the lactate/pyruvate ratio in the brain $1 \mathrm{~h}$ before and 1 and $2 \mathrm{~h}$ after moderate $\mathrm{HV}$ are reported in Table 4. No significant changes were observed.

\section{Discussion}

\section{Main findings}

The aim of this study was to detect possible adverse effects of moderate HV in patients with severe TBI during the acute phase postinjury. To our knowledge, this is the first study using a multimodal monitoring set (MD, $\mathrm{PbrO}_{2}$, and TCCD, together with ICP and CPP) to investigate this.

Our data suggest that moderate short-term HV was effective in lowering ICP with a remarkable effect on CBF velocities, as shown by the reduction of the CBFV in the MCAs bilaterally and by a slight increase in PI. The CBFV in the MCAs in the study population at baseline was normal, suggesting a physiological global CBF. In the course of moderate $\mathrm{HV}, \mathrm{CBFV}$ and hence $\mathrm{CBF}$ decreased significantly, as in previous studies [17, 18]. These findings are consistent with vasoconstriction in the brain vasculature leading to a reduction in $\mathrm{CBF}$ and likely in CBV.

MAP and HR remained stable during moderate $\mathrm{HV}$, as demonstrated by Minhas et al. [13] in volunteers. However, in patients receiving positive pressure ventilation, sedation, and hypovolemia, the interactions between hypocapnia and hemodynamics are more complex [2]. Due to the possible systemic effects of hypocapnia, patients with persisting hypovolemia or hemodynamic instability despite previous fluid resuscitation were excluded.

Our work included two additional variables, $\mathrm{PbrO}_{2}$ and MD, with the specific aim of demonstrating possible tissue hypoxia and/or disturbed metabolic patterns.

On the basis of our results, there was a $\mathrm{PbrO}_{2}$ reduction, but within a physiological range. Additionally, MD with a stable Lactate/pyruvate $(\mathrm{L} / \mathrm{P})$ ratio was not indicative of an energy crisis.

Table 3 Transcranial color-coded duplex sonography variables measured in middle cerebral arteries bilaterally

\begin{tabular}{|c|c|c|c|c|}
\hline$n=11$ & $\begin{array}{l}\text { A } \\
\text { Baseline }\end{array}$ & $\begin{array}{l}\text { C } \\
\text { Moderate hyperventilation }\end{array}$ & $\begin{array}{l}\text { D } \\
50 \text { min of moderate hyperventilation }\end{array}$ & $\begin{array}{l}\text { E } \\
\text { Return to baseline }\end{array}$ \\
\hline CBFV right $(\mathrm{cm} / \mathrm{s})$ & $81(23)$ & $69(21)^{*}$ & $71(20)^{*}$ & $77(28)$ \\
\hline CBFV left $(\mathrm{cm} / \mathrm{s})$ & $80(22)$ & $66(17)^{*}$ & $63(15)^{*}$ & $75(24)^{9 \mp}$ \\
\hline PSV right $(\mathrm{cm} / \mathrm{s})$ & $136(37)$ & $117(34)^{*}$ & $120(33)^{*}$ & $129(42)$ \\
\hline PSV left $(\mathrm{cm} / \mathrm{s})$ & $131(35)$ & $110(25)^{*}$ & $107(24)^{*}$ & $126(37)^{9 \mp}$ \\
\hline EDV right $(\mathrm{cm} / \mathrm{s})$ & $56(20)$ & $45(16)^{*}$ & $46(16)^{*}$ & $51(22)^{\natural}$ \\
\hline EDV left $(\mathrm{cm} / \mathrm{s})$ & $54(16)$ & $43(13)^{*}$ & $41(11)^{*}$ & $52(17)^{9 \mp}$ \\
\hline Pl right & $1.03(0.17)$ & $1.08(0.16)$ & $1.05(0.23)$ & $1.05(0.17)$ \\
\hline PI left & $0.96(0.15)$ & $1.06(0.10)$ & $1.07(0.14)^{*}$ & $1.02(0.14)$ \\
\hline
\end{tabular}

Abbreviations: $A$ Baseline, $B$ Increasing minute ventilation, $C$ Begin moderate hyperventilation with target $\mathrm{PaCO} \mathrm{C}_{2} 4-4.7 \mathrm{kPa}, D$ After moderate hyperventilation for $50 \mathrm{~min}, E$ Return to baseline. CBFV Mean flow velocity of the middle cerebral artery $(\mathrm{cm} / \mathrm{s}), P S V$ Peak systolic velocity $(\mathrm{cm} / \mathrm{s}), E D V$ End-diastolic velocity $(\mathrm{cm} / \mathrm{s}), P I$ Pulsatility index

* $p<0.05$ compared with A

I $p<0.05$ compared with $C$

$\mp p<0.05$ compared with $\mathrm{D}$

$N=11$ patients, $+=10$ patients. Data are expressed as mean (SD) 
Table 4 Cerebral microdialysis

\begin{tabular}{llll}
\hline$n=9$ & Baseline $(\mathrm{A}-1 \mathrm{~h})$ & $\begin{array}{l}1 \mathrm{~h} \text { after moderate hyperventilation } \\
\text { for } 50 \mathrm{~min}(\mathrm{D}+1 \mathrm{~h})\end{array}$ & $\begin{array}{l}2 \mathrm{~h} \text { after moderate hyperventilation } \\
\text { for } 50 \text { min }(\mathrm{D}+2 \mathrm{~h})\end{array}$ \\
\hline Brain glucose $(\mathrm{mmol} / \mathrm{L})$ & $1.5(1.0)^{\Phi}$ & $1.4(0.7)$ & $1.4(0.7)$ \\
Brain lactate $(\mathrm{mmol} / \mathrm{L})$ & $3.3(1.0)^{\Phi}$ & $3.5(1.3)$ & $3.4(1.4)$ \\
Brain pyruvate $(\mu \mathrm{mol} / \mathrm{L})$ & $101.4(38.3)^{\Phi}$ & $99.6(39.5)$ & $97.3(44.7)^{\Phi}$ \\
LP ratio & $34.2(8.2)^{\Phi}$ & $39.0(17.7)$ & $37.5(11.4)^{\Phi}$ \\
\hline
\end{tabular}

LP Lactate/pyruvate ratio

Data are expressed as mean (SD). $N=9$ patients

${ }^{\oplus}$ Eight patients

\section{What is already known}

In the last 30 years, HV has been fiercely debated. After initial widespread use [19], the effects of HV on outcome were questioned in a randomized study [20]. That study included a total of 113 patients in 3 groups and used different levels of $\mathrm{HV}$ in all arms. ICP was kept stable in all groups. At 3 and 6 months after injury, patients with a motor score of 4-5 in the hyperventilation group had less favorable outcomes than the other groups. However, the control group was hyperventilated and had a $\mathrm{PaCO}_{2}$ of $31-32 \mathrm{mmHg}$ for the first 5 study days. Additionally, HV was induced prophylactically, regardless of ICP.

More accurate studies of pathophysiological changes induced by HV have been performed by two authoritative groups. Coles et al. measured a significant reduction of CBF with PET scans and an increase in the volume of severely hypoperfused tissue following HV [4] with a $\mathrm{PaCO}_{2}$ reduction from 4.8 to $3.9 \mathrm{kPa}$. Diringer et al., on the contrary, using an analogous PET technique, did not disclose any alteration of oxygen metabolism in two groups of patients with TBI managed with different degrees of HV [17]. They concluded that oxygen metabolism was maintained due to the low baseline metabolic rate and compensatory increase in oxygen extraction fraction.

\section{How our data compare with the literature: limitations}

Our data questioned if $\mathrm{HV}$, even when effective in reducing $\mathrm{CBF}$ and ICP, induced measurable changes compatible with true ischemia (defined as a CBF insufficient for preserving adequate tissue oxygenation and metabolism). For a fair comparison with the existing evidence, however, the study limitations should be acknowledged. First, the small sample size limits the generalizability of the findings. More accurate analyses, for instance looking at sex differences in vasoreactivity or association between PI and outcome, were clearly not feasible [21, 22]. Second, we decided to perform only a moderate degree of short-term HV. This choice was dictated by two concerns: the risk of ischemia and the time frame of the test. We were aware that the brain is especially vulnerable to ischemia during the acute phase after trauma [23]. It may well be that we did not detect pathological changes because of the mild level of hypocapnia used for a short time interval. Third, the MD and $\mathrm{PbrO}_{2}$ probes explore only small areas of the brain; therefore, we cannot exclude concomitant changes in other brain regions [24, 25].

In our study population, however, the MD and the $\mathrm{PbrO}_{2}$ probes were placed, in the majority of the cases, in the most injured hemisphere of the brain. Interestingly, the cerebral glucose at baseline was normal, whereas the $\mathrm{L} / \mathrm{P}$ ratio at baseline was markedly increased and pathological [26], reflecting tissue injury despite "normal" parenchyma on the CT scan. From this point of view, we were exploring a vulnerable portion of the brain, where potential side effects of HV would have been more likely to be detected. Furthermore, because none of the probes were placed directly in the site of contusion and only two were in pericontusional tissue, the effect of $\mathrm{HV}$ on $\mathrm{PbrO}_{2}$ should not have been compromised [24].

\section{Conclusions}

Our findings add evidence to the belief that a moderate degree of short-term $\mathrm{HV}$ is effective in reducing ICP through CBFV modifications as an estimation of CBF. Furthermore, a moderate degree of $\mathrm{HV}$ reduces $\mathrm{PbrO}_{2}$, but within a physiological range, and does not significantly change the cerebral energy metabolism. Further investigations of prolonged and more severe $\mathrm{HV}$, in the context of intracranial hypertension and in a larger study population, are needed to characterize the risks and benefits of $\mathrm{HV}$ in severe TBI.

\author{
Acknowledgements \\ Not applicable. \\ Funding \\ None. \\ Availability of data and materials \\ The datasets used and/or analyzed during the current study are available \\ from the corresponding author on reasonable request. \\ Authors' contributions \\ GB helped in the conception and design of the study; the acquisition, \\ analysis, and interpretation of data; and drafting the work and revising it
}


critically for key content. NS helped in the interpretation of data, as well as in drafting the work and revising it for key content. AP helped in the analysis and interpretation of data, as well as in revising the work for key content. FS helped in the acquisition of data and critical revision of key content. PS helped in the conception and design of the study. SK helped in the conception and design of the study, the acquisition of data, and revising the work critically for key content. All authors read and approved the final manuscript.

\section{Ethics approval and consent to participate}

The Institutional Ethics Committee of Zurich approved the research protocol of this prospective clinical trial (KEK-ZH 2012-0542). Informed consent was obtained from the patients' next of kin prior to study enrollment and/or from the patients after ICU discharge.

\section{Consent for publication}

Not applicable.

\section{Competing interests}

The authors declare that they have no competing interests.

\section{Publisher's Note}

Springer Nature remains neutral with regard to jurisdictional claims in published maps and institutional affiliations.

\author{
Author details \\ 'Institute for Intensive Care Medicine, University Hospital of Zurich, \\ Rämistrasse 100, 8091 Zurich, Switzerland. ${ }^{2}$ Department of Physiopathology \\ and Transplantation, Milan University and Neuro ICU Fondazione IRCCSCà \\ Granda Ospedale Maggiore Policlinico Milan, Milan, Italy. ${ }^{3}$ Unit of Clinical \\ Epidemiology, Ente Ospedaliero Cantonale, Bellinzona, Switzerland. \\ ${ }^{4}$ Department of Intensive Care, Westmead Hospital, Westmead, NSW 2145, \\ Australia.
}

Received: 29 September 2018 Accepted: 26 December 2018 Published online: 13 February 2019

\section{References}

1. Muizelaar JP, van der Poel HG, Li ZC, Kontos HA, Levasseur JE. Pial arteriolar vessel diameter and $\mathrm{CO} 2$ reactivity during prolonged hyperventilation in the rabbit. J Neurosurg. 1988;69(6):923-7.

2. Stocchetti N, Maas Al, Chieregato A, van der Plas AA. Hyperventilation in head injury: a review. Chest. 2005;127(5):1812-27.

3. Godoy DA, Seifi A, Garza D, Lubillo-Montenegro S, Murillo-Cabezas F. Hyperventilation therapy for control of posttraumatic intracranial hypertension. Front Neurol. 2017;8:250.

4. Coles JP, Minhas PS, Fryer TD, Smielewski P, Aigbirihio F, Donovan T, et al. Effect of hyperventilation on cerebral blood flow in traumatic head injury: clinical relevance and monitoring correlates. Crit Care Med. 2002; 30(9):1950-9.

5. Coles JP, Fryer TD, Coleman MR, Smielewski P, Gupta AK, Minhas PS, et al. Hyperventilation following head injury: effect on ischemic burden and cerebral oxidative metabolism. Crit Care Med. 2007;35(2):568-78.

6. Diringer MN, Yundt K, Yideen TO, Adams RE, Zazulia AR, Deibert E, et al. No reduction in cerebral metabolism as a result of early moderate hyperventilation following severe traumatic brain injury. J Neurosurg. 2000; 92(1):7-13.

7. Chesnut RM, Temkin N, Dikmen S, Rondina C, Videtta W, Petroni G, et al. A method of managing severe traumatic brain injury in the absence of intracranial pressure monitoring: the imaging and clinical examination protocol. J Neurotrauma. 2018;35(1):54-63.

8. Le Roux P, Menon DK, Citerio G, Vespa P, Bader MK, Brophy GM, et al. Consensus summary statement of the International Multidisciplinary Consensus Conference on Multimodality Monitoring in Neurocritical Care: a statement for healthcare professionals from the Neurocritical Care Society and the European Society of Intensive Care Medicine. Intensive Care Med. 2014;40(9):1189-209.

9. Rosenthal G, Hemphill JC 3rd, Sorani M, Martin C, Morabito D, Obrist WD, et al. Brain tissue oxygen tension is more indicative of oxygen diffusion than oxygen delivery and metabolism in patients with traumatic brain injury. Crit Care Med. 2008;36(6):1917-24.
10. Rohlwink UK, Zwane E, Fieggen AG, Argent AC, le Roux PD, Figaji AA. The relationship between intracranial pressure and brain oxygenation in children with severe traumatic brain injury. Neurosurgery. 2012;70(5):122030 discussion 1231.

11. Eriksson EA, Barletta JF, Figueroa BE, Bonnell BW, Vanderkolk WE, McAllen KJ, et al. Cerebral perfusion pressure and intracranial pressure are not surrogates for brain tissue oxygenation in traumatic brain injury. Clin Neurophysiol. 2012;123(6):1255-60.

12. Ainslie PN, Celi L, McGrattan K, Peebles K, Ogoh S. Dynamic cerebral autoregulation and baroreflex sensitivity during modest and severe step changes in arterial PCO2. Brain Res. 2008;1230:115-24.

13. Minhas JS, Panerai RB, Robinson TG. Modelling the cerebral haemodynamic response in the physiological range of PaCO2. Physiol Meas. 2018;39(6): 065001.

14. McCarville MB, Goodin GS, Fortner G, Li CS, Smeltzer MP, Adams R, et al. Evaluation of a comprehensive transcranial Doppler screening program for children with sickle cell anemia. Pediatr Blood Cancer. 2008;50(4):818-21.

15. Klinzing S, Steiger P, Schupbach RA, Bechir M, Brandi G. Competence for transcranial color-coded duplex sonography is rapidly acquired. Minerva Anestesiol. 2015;81(3):298-304.

16. Zweifel C, Czosnyka M, Carrera E, de Riva N, Pickard JD, Smielewski P. Reliability of the blood flow velocity pulsatility index for assessment of intracranial and cerebral perfusion pressures in head-injured patients. Neurosurgery. 2012;71(4):853-61.

17. Diringer MN, Videen TO, Yundt K, Zazulia AR, Aiyagari V, Dacey RG Jr, et al Regional cerebrovascular and metabolic effects of hyperventilation after severe traumatic brain injury. J Neurosurg. 2002;96(1):103-8.

18. Cold GE. Does acute hyperventilation provoke cerebral oligaemia in comatose patients after acute head injury? Acta Neurochir (Wien). 1989; 96(3-4):100-6.

19. Obrist WD, Langfitt TW, Jaggi JL, Cruz J, Gennarelli TA. Cerebral blood flow and metabolism in comatose patients with acute head injury: relationship to intracranial hypertension. J Neurosurg. 1984;61(2):241-53.

20. Muizelaar JP, Marmarou A, Ward JD, Kontos HA, Choi SC, Becker DP, et al. Adverse effects of prolonged hyperventilation in patients with severe head injury: a randomized clinical trial. J Neurosurg. 1991;75(5):731-9.

21. Minhas JS, Panerai RB, Robinson TG. Sex differences in cerebral haemodynamics across the physiological range of $\mathrm{PaCO}$. Physiol Meas. 2018;39(10):105009.

22. Minhas JS, Panerai RB, Ghaly G, Divall P, Robinson TG. Cerebral autoregulation in hemorrhagic stroke: a systematic review and metaanalysis of transcranial Doppler ultrasonography studies. J Clin Ultrasound. 2019:47(1):14-21.

23. Bouma GJ, Muizelaar JP, Choi SC, Newlon PG, Young HF. Cerebral circulation and metabolism after severe traumatic brain injury: the elusive role of ischemia. J Neurosurg. 1991;75(5):685-93.

24. Hawryluk GW, Phan N, Ferguson AR, Morabito D, Derugin N, Stewart CL, et al. Brain tissue oxygen tension and its response to physiological manipulations: influence of distance from injury site in a swine model of traumatic brain injury. J Neurosurg. 2016;125(5):1217-28.

25. Willie CK, Macleod DB, Shaw AD, Smith KJ, Tzeng YC, Eves ND, et al. Regional brain blood flow in man during acute changes in arterial blood gases. J Physiol. 2012;590(14):3261-75.

26. Reinstrup P, Stahl N, Mellergard P, Uski T, Ungerstedt U, Nordstrom CH. Intracerebral microdialysis in clinical practice: baseline values for chemical markers during wakefulness, anesthesia, and neurosurgery. Neurosurgery. 2000:47(3):701-9 discussion 9-10.

Ready to submit your research? Choose BMC and benefit from:

- fast, convenient online submission

- thorough peer review by experienced researchers in your field

- rapid publication on acceptance

- support for research data, including large and complex data types

- gold Open Access which fosters wider collaboration and increased citations

- maximum visibility for your research: over $100 \mathrm{M}$ website views per year

At $\mathrm{BMC}$, research is always in progress.

Learn more biomedcentral.com/submissions 